\title{
A influência do tecnodiscurso nas análises em linguística
}

\author{
Jessica Oliveira FERNANDES (1) \\ Universidade Federal do Ceará (UFC)
}

\section{RESUMO}

Nesta mesa, a proposta da analista do discurso Marie-Anne Paveau é apresentada pelos professores Roberto Baronas, Ana Carolina Vilela-Ardenghi e Júlia Lourenço Costa, participantes da equipe de tradução do dicionário Análise do Discurso Digital: dicionário das formas e das práticas, o qual ainda está em fase de revisão técnica. O professor Baronas inicia destacando os percursos de contato com a teoria proposta por Marie-Anne Paveau; em seguida a professora Ana Carolina discute questões sobre prédiscursos e sua relação com a moral; novamente Baronas toma a palavra e apresenta as características do tecnodiscurso, posteriormente passa a palavra à professora Júlia, que faz algumas considerações acerca do militantismo digital por meio da análise de textos nativos digitais. A mesa é, en-

OPEN ACCESS

EDITADO POR

Raquel Freitag

AVALIADO POR

Mariana Barros

DATAS

Recebido: 12/07/2020

Aceito: $11 / 08 / 2020$

Publicado: 14/08/2020

COMO CITAR

Fernandes, J. O. (2020).

A influência do tecnodiscurso

nas análises em linguística.

Revista da Abralin, v. 19, n. 2, p.

$1-4,2020$. tão, finalizada com a mediação, pela professora Mariana de Barros, das perguntas feitas aos membros da mesa pelo chat.

RÉSUMÉ

Sur ce tableau, la proposition de l'analyste de discours Marie-Anne Paveau est présentée par les professeurs Roberto Baronas, Ana Carolina Vilela-Ardenghi et Júlia Lourenço Costa, participants à l'équipe de traduction du dictionnaire Digital Discourse Analysis: dictionnaire des formes et pratiques, le qui est en cours d'examen technique. Le professeur Baronas commence par mettre en évidence les voies de contact avec la théorie proposée par Marie-Anne Paveau; puis la professeur Ana Carolina discute des questions sur les pré-discours et leur relation avec la morale; Baronas prend à nouveau la parole et présente les caractéristiques du technodiscours, puis conclut la présentation de la théorie avec le professeur Júlia, qui fait quelques réflexions sur le militantisme numérique à travers 


\section{REVISTA DA ABRALIN}

l'analyse de textes natifs numériques. Le tableau se termine par la médiation, par la professeure Mariana de Barros, des questions posées aux membres de ce table au chat.

PALAVRAS-CHAVE

Análise do discurso digital. Pré-discursos. Tecnodiscursos.

MOTS-CLÉS

L'analise du discours numerique. Pré-discours. Technodiscours

A mesa-redonda resenhada foi transmitida em formato on-line pela Associação Brasileira de Linguística (ABRALIN), no dia 05 de julho de 2020, e conta com a mediação da professora Mariana de Barros e com a apresentação dos professores Roberto Baronas, Ana Carolina Vilela-Ardenghi e Júlia Lourenço Costa acerca dos estudos da autora Marie-Anne Paveau, uma analista do discurso francesa, sobre os discursos nativos digitais, os quais são de suma relevância para os usos atuais da linguagem em ambiente virtual.

A apresentação dos participantes da mesa é feita pela mediadora, professora Mariana de Barros, a qual explica a divisão da exposição feita pelos professores, a saber: o professor Baronas inicia destacando os percursos de contato com a teoria proposta por Marie-Anne Paveau; em seguida a professora Ana Carolina discute questões sobre pré-discursos e sua relação com a moral; novamente Baronas toma a palavra e apresenta as características do tecnodiscurso, para então finalizar a apresentação da teoria com a professora Júlia, que faz algumas considerações acerca do tecnodiscurso no militantismo digital por meio da análise de textos nativos digitais.

O professor Baronas discorre acerca dos primeiros contatos com a autora em questão e aponta o início desse diálogo em 2008, com o texto Palavras Anteriores: os pré-discursos entre a memória e a cognição, em que Paveau destaca um aspecto que não figura com costume nas reflexões de analistas do discurso, a cognição. O professor ainda destaca que o pré-construído é uma das formas de manifestação dos pré-discursos. Em 2013, apresentado ao livro Os pré-discursos: sentido, memória e cognição por Sírio Possenti, Baronas e outros pesquisadores se debruçaram sobre discussões levantadas nessa obra. Em 2016, Possenti apresenta ao grupo de estudos que coordena (FEsTA) mais uma obra de Marie-Anne Paveau, Linguagem e moral: uma ética das virtudes discursivas, a qual também foi alvo de inúmeros debates. Mais recentemente, o grupo tem debatido acerca da obra Análise do Discurso Digital: dicionário das formas e das práticas, a qual está em fase de tradução com publicação prevista para o ano de 2020.

Em seguida, a professora Ana Carolina discorre acerca dos conceitos de pré-discurso e, também, sobre a relação entre linguagem e moral, base epistemológica que constitui os pensamentos da pesquisadora francesa. Em sua fala, Ana Carolina destaca o empreendimento de Paveau em relação a 


\section{REVISTA DA ABRALIN}

dotar a Análise do Discurso de uma dimensão cognitiva, segundo ela, bastante frutífera. Paveau entende cognição como "os processos de construção de conhecimentos e sua configuração no discurso a partir de dados recebidos pelos sentidos, pela memória e pelas relações sociais" (2013, p. 9), aproximando-se da ideia de cognição sociocultural, isto é, não se resume a processos exclusivamente mentais. É a partir de uma aproximação com estudos cognitivos que a autora desenvolve o conceito de anterioridades discursivas ou pré-discurso, a saber: "um conjunto de quadros pré-discursivos coletivos (saberes, crenças, práticas), que dão instruções para a produção e a interpretação do sentido do discurso" (2013, p. 130). É válido ressaltar, ainda, que, apesar de entender os pré-discursos como fatores que antecedem a materialização discursiva e que a orientam, a pesquisadora não os entende como extralinguísticos.

Após exemplificar os quadros pré-discursivos e a sua interferência no que diz respeito à construção de sentidos, a professora Ana Carolina discorre sobre a relação linguagem e moral, um outro empreendimento ao qual Paveau se dedica, momento em que busca responder perguntas como "O que pode ser entendido como ofensivo ou não em determinada comunidade de fala?". A virtude dos enunciados é, então, foco de sua discussão e diz respeito ao compromisso do falante em se ajustar à situação e a seu interlocutor, considerando seus valores e crenças, proposta que considera, também, o fator cognição. A noção de virtude dos enunciados possui algumas propriedades constitutivas, a saber: a) a existência - reações morais ao discurso - , b) a disposição reflexiva - discursos como resultado de ajustes a agentes-falantes - e c) a plasticidade axiológica - valores negociáveis, atualizáveis. Então, é possível observar a continuidade dessas reflexões, uma vez que o entendimento de ética e moral dos enunciados produzidos está intimamente relacionado com os pré-discursos, isto é, com a memória e a cognição. Há, então, um lugar à agentividade do sujeito, colocando-o como clivado e não mais apenas como sobredeterminado.

Novamente com a palavra, o professor Baronas discorre acerca da noção de tecnodiscurso conforme Paveau. Com uma profusão cada vez mais corrente dos discursos nativos digitais, os quais a autora intitula tecnodiscursos, ela propõe uma reflexão, especificamente em seu dicionário, acerca de conceitos os quais, calcados na análise do discurso de orientação francesa, nos fazem repensar questões teórico-metodológicas de análises feitas dos discursos nativos de redes sociais, por exemplo. A influência do aparato técnico na produção e compreensão desses tecnodiscursos é ponto principal para repensar algumas características próprias desses ambientes, como a clicabilidade, e como esses traços particulares (linguageiros e técnicos) impactam grande parte das análises até então feitas, segundo a autora, o que ela chama de análises logocêntricas, em que a internet é usa da para corpus, não como corpus. Essa distinção destaca e critica a prática corrente de retirada de enunciados do seu contexto nativo digital; diante disso, a autora propõe não mais considerar a máquina como um componente externo à linguagem, como feito nas tradicionais abordagens logo e antropocêntricas, mas sob uma perspectiva ecológica, a qual integra produções linguageiras a determinações técnicas.

Com o intuito de chamar a atenção para características particulares dos tecnodiscursos e de como elas interferem na construção de sentidos, Paveau descreve seis traços: 1. A composição (a 


\section{REVISTA DA ABRALIN}

possibilidade de integração de diversas semioses); 2. A deslinearização (possibilidades clicáveis que direcionam o leitor para outros textos, em outras páginas); 3. A ampliação (os enunciados são, em alguns casos, atualizados por meio de comentários); 4. A relacionacionalidade (menções com @ e hashtags que ligam textos entre si); 5. A investigabilidade (os discursos são rastreáveis, por exemplo, por meio de sites de busca) e 6. A imprevisibilidade. Todas essas características são exemplificadas e explicadas pelo professor por meio da análise de alguns textos nativos digitais com a temática Marielle Franco.

Para finalizar, a professora Júlia Costa apresenta inquietações sobre enunciador digital, discussões mais recentes da pesquisadora Marie-Anne Paveau. Sua fala na mesa se pauta no verbete dualismo digital e parte da polarização entre real e virtual. A pesquisadora francesa questiona essa divisão e propõe uma visão integralista entre homem e máquina, em que os discursos são coconstruídos juntamente com as determinações técnicas. A enunciação é, nessa proposta, questionada, uma vez que a identidade única do eu e as noções de tempo e espaço são modificadas no universo digital, o que tem implicações no uso da linguagem. Sendo assim, a noção de enunciador é, para Paveau, ampliada, pois a pesquisadora considera as dimensões individual e coletiva, corroborando a ideia de ampliação característica dos tecnodiscursos, por exemplo, por meio dos comentários ou da escrita colaborativa online, como pode ocorrer com o uso da ferramenta Google Docs. Júlia segue sua exposição ilustrando o que discutiu teoricamente ao analisar algumas manifestações digitais, momento em que exemplifica como as noções de eu enunciador, de lugar, de espaço da enunciação são ampliadas em uma manifestação realizada em diversas redes sociais, como Twitter e Facebook, e, ainda, na janela de casa, por meio da participação em um panelaço.

Por último, a mediadora Mariana de Barros seleciona algumas perguntas acerca das apresentações, as quais são respondidas ou comentadas pelos debatedores. As perguntas ajudam a esclarecer o caráter instigador da proposta de Marie-Anne Paveau e seus impactos nas análises dos discursos digitais.

\section{REFERÊNCIAS}

ANÁLISE do Discurso Digital proposta por Marie-Anne Paveau: dos pré-discursos aos tecnodiscursos. Conferência apresentada por Roberto Leiser Baronas, Ana Carolina Vilela-Ardenghi, Júlia Lourenço Costa [s.l., s.n], 2020. 1 vídeo (2h 14min 10s). Publicado pelo canal da Associação Brasileira de Linguística. Disponível em: https://youtu.be/nt4vQChkW-g. Acesso em: 07 jul 2020.

PAVEAU, M.-A. Os pré-discursos: sentido, memória e cognição. Campinas, SP: Pontes Editores, 2013.

PAVEAU, M.-A. Linguagem e moral: uma ética das virtudes discursivas. Campinas, SP: Editora da Unicamp, 2015.

PAVEAU, M.-A. Análise do Discurso Digital: dicionário das formas e das práticas. Campinas, SP: Pontes Editores, 2020 (no prelo). 